\title{
T-Tube Conformational Stent with Aspiration Used in Dacryocystorhinostomy
}

\author{
RAZVAN HAINAROSIE ${ }^{1,2}$, ANDREEA RUSESCU ${ }^{1}$, CATALINA PIETROSANU1*, IRINA IONITA ${ }^{1}$, MURA HAINAROSIE ${ }^{1}$, \\ DRAGOS CRISTIAN STEFANESCU ${ }^{3}$, VIOREL ZAINEA ${ }^{1,2}$, ALINA POPA CHERECHEANU ${ }^{1,4}$ \\ ${ }^{1}$ Carol Davila University of Medicine and Pharmacy, 8th Eroii Sanitari Blvd., 050474, Bucharest, Romania \\ 2 Prof. Dr. D. Hociota Institute of Phonoaudiology and Functional ENT Surgery, 21st Mihail Cioranu Str.,050751,Bucharest, Romania \\ ${ }^{3}$ Gen. Dr. Aviator Victor Anastasiu Institute of Aeronautical and Spatial Medicine,88th Mircea Vulcanescu Str., 010825, Bucharest, \\ Romania \\ ${ }^{4}$ Emergency Universitary Hospital Bucharest, Department of Ophtalmology, 169 th Splaiul Independentei Str., 050098, Bucharest, \\ Romania
}

\begin{abstract}
The development and increase use of the endoscopic techniques in endonasal surgery has encouraged the practice of endoscopic dacryocystorhinostomy as a trustworthy alternative to external dacryocystorhinostomy. The purpose of the present paper is to provide another insight into transnasal endoscopic dacryocystorhinostomy by proposing the fitting, at the end of the intervention, of a conformational stent model with aspiration made out of medical silicone similar to a Montgomery tube.
\end{abstract}

\section{Keywords:conformational stent with aspiration, model proposal, transnasal endoscopic dacryocystorhinostomy}

Endoscopic surgery has seen a remarkable development over the past decades, providing surgeons with a minimally invasive and safe way when dealing with complex surgical interventions, at least as far as the sinonasal area is concerned.

The complexity of the technique and the variability of the used technologies as well as the angulations of the endoscopes allow for greater flexibility of the surgical approach but also the realization of a wide range of surgical interventions that until some time ago could only be achieved through an external approach.

One of the interventions that has seen a change in the surgical approach is dacryocystorhinostomy, which was classically made by the external technique and nowadays the transnasal endoscopic technique is preferred and frequentlyused.

This procedure aims to achieve a direct drainage of tears by opening the lacrimal sac at the level of the nasal cavity when there is an obstruction of the nasolacrimal duct (NLD).

Dacryocystorhinostomy (DCR) is a procedure that has been practiced for over a century, described throughout the history of medicine as a way of creating a drainage pathway for tears either by using a cauteryon the lacrimal bone or by opening the lacrimal sac in the maxillary sinus and further placing a gold or silver stent, but the success rates of these interventions did not exceed more than $80 \%$ of the cases.

Currently transnasal endoscopic DCR is used in cases of NLD whose obstruction is evident in facial trauma, external DCR failure, as well as in young people with anatomic variations or congenital malformations of the lacrimal pathway. This technique is questionable to be used in cases of acute dacryocytitis or anticoagulant treatments that can notbe stopped and itis eminently forbidden to be performed in the case of lacrimal sac tumors.

In case of insufficient opening of the lacrimal sac at the end of the surgery, it could be taken into consideration fitting a stent to ensure permeability and, implicitly, drainage of tears into the nasal cavity.
Various types of stents have been used over time to achieve permeability of the post-interventional lacrimal pathway and support the healing process by guiding to define a new drainage system.

Technological evolution has led to the developmentand use of medical silicone, a polymer chain whose structure is centrally held together by oxygen bonds with a very low overall molecular polarity, which gives it hydrophobic properties, resistance to oxidation and aging. Additionally, the structure of this polymer contains Si-C and Si-O polar groups similar to ionic bonds, which provide an extraordinary heat resistance performance and good biocompatibility

Due to its remarkable properties, as high breathability and permeability, medical silicone is used to create a wide range of medical devices, including the lacrimal mounted stents after DCR in which case, the indicated material, seems to be a viable and successful option so far.

The purpose of the present paper is to provide another insight into transnasal endoscopic dacryocystorhinostomy by proposing the fitting, at the end of the intervention, of a conformational stent model with aspiration, made out of medical silicone similar to a Montgomery tube.

\section{Experimental part}

Transnasal endoscopic dacryocystorhinostomy is realized under general anesthesia and transoral intubation. Under endoscopic control, septoplasty is performed if the septum through its structure blocks the access to the median mediatus, then medialization of the middle turbinate is performed to reveal the lacrimal crest, the uncinate process and the bulla ethmoidalis. A vertical incision is made at the anterior limit of the lacrimal crest from the insertion of the middle turbinate and descending to the upper limit of the inferior turbinate. The next step is represented by two horizontal incisions parallel to each other and placed at the extremities of the incision described above, from the anterior to the posterior sides of the lacrimal crest. By lifting the obtained flap, the lacrimal bone will be visualized which will be drilled on an as large 
surface as possible in order to identify the medial wall of the lacrimal sac (fig. 1.). This latter action is facilitated by the use of a Bowman cannula that is inserted into the inferior canaliculus (fig. 4.). Following, the incision of the medial wall ( fig. 2.) of the lacrimal sac in performed, in an $H$ shape, with the endoscopic scalpel to obtain a wide opening of the lacrimal sac (fig. 3.).

There are situations where it is necessary to mount a local stent in order to ensure proper postoperative drainage to the nasal cavity of tears.

Through this paper, we want to propose a stent model made of medical silicone primary monocannal tube with a lateral angulated branch faced towards the nasal cavity which helps the appropriate postoperative drainage with the possibility of attaching a suction cannula to this arm and a general conformation similar to a Montgomery TTube (fig. 4.)

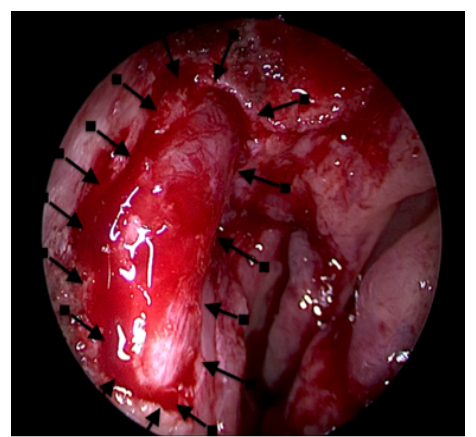

Fig. 1. Identifying the medial wall of the lacrimal sac (here there is a tension of the wall probably due to a collection found in the lacrimal sac)

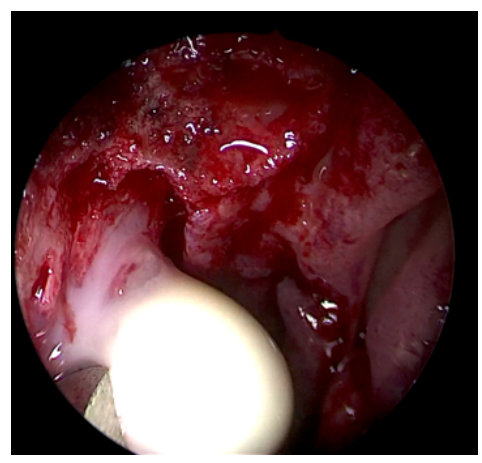

Fig. 2. Incision on the medial wall of the lacrimal sac and purulent collection evacuation

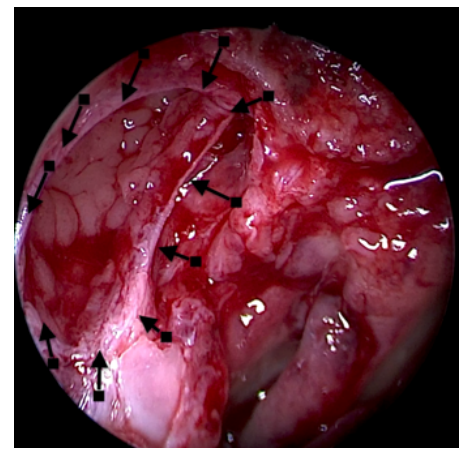

Fig. 3. Opening of the lacrimal sac

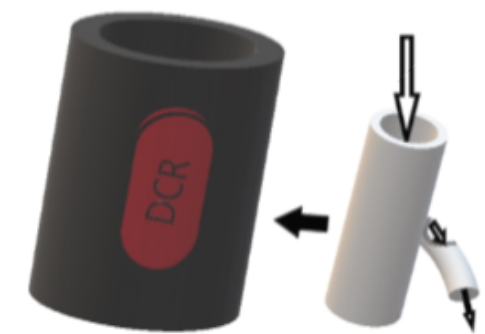

Fig. 4. Conformational Silicone Stent for DCR resembling a Montgomery T-tube

This type of stent is thought to have initially inserted the distal partinto the lacrimal sac, then by vertical movement, from inferior to superior, to insert its lower part facing the Hasner valve. The angulated branch remains outside the dacryocystorhinostomy opening to the nasal cavity to provide continuous drainage.

\section{Results and discussions}

The structure proposed by the monocanal character of the main arm and the angled lateral branch, as well as the light insertion technique indicates a high local adaptability, but requires a detailed study for accurate calculation of the material thickness and inner angulation of the drainage corridor to be able to provide the whole concept a functionality as high as possible.

Also a real import is the aspect of the free end of the structure to the nasal cavity with the analysis of the possibility of adapting a suction cannula and its dimensions so as not to determine an important obstruction of the medium meatus

Considering the development of medical silicone and its properties that ensure a good biocompatibility and increased its utility rate in various medical areas, we expect that the proposed model will not meet a high rate of complications like those mentioned in the literature in previous years, such as placement granuloma and subsequent obstruction of the stent.

\section{Conclusions}

Out of the need to increase the success rate of the intervention taken in question, but also because of controversial discussions about whether or not stenting postDCR is a good option and evaluating the complications occurring after the surgery, it is advisable to develop a model that ensures good local permeability and drainage of postoperative tears.

Thus, it is necessary to investigate in detail the features of this proposed model and to carry out other studies that highlight the results obtained and the subsequent feasibility of the concept.

\section{References}

1. VLADIMIR, S.Y., JOSEPH, C.F., DANIEL, A., BETSY, P.L., Saudi. J. Ophthalmol, 25, nr. 1, 2011 JAN, p. 37-49

2. NUSSBAUMER, M., SCHREIBER, S., YUNG, M.W., J Laryngol Otol., 118,2004, p267-269

3. UNLU, H.H., GUNHAN, K., BASER, E.F., et al., Otolaryngol Head Neck Surg., 140, 2009, p.589-595

4. DEMARCO, R., STROSE, A., ARAUJ O, M., et al., Otolaryngol Head Neck Surg., 137, 2007, p.497-499

5. BAJ AJ, M.S., PUSHKER, N., BALASUBRAMANYA, R., RANI, A., Br. J. Ophthalmol., 86, nr. 12, 2002 Dec, p. 1460

6. SYED, MI., HENDRY, J., CAIN, AJ ., WILLIAMS, AT., Ann R Coll Surg Engl., 96, nr. 2, 2014 MAR, p.173-174

7. MOHAMAD, S.H., KHAN, I., SHAKEEL, M., NANDAPALAN, V., Ann R Coll Surg Engl., 95, nr. 3, 2013 APR, p.196-199

8. MANN, B.S., WORMALD, P. ., Laryngoscope, 116, 2006, p.1172-1174 9. SMIRNOV, G., TUOMILEHTO, H., TERASVIRTA, M., etal., AmJ Rhinol., 20, 2006, p.600-602

10. SMIRNOV, G., TUOMILEHTO, H., TERASVIRTA, M., et al., Am J Rhinol., 22, 2008, p. 214-217

11. CHUANG QI, X., LINGLING, Z., YANG, L., HONG, M., SHUZHEN, L., Sci. Rep., 7, 2017, p.1936

12. MELIKE, B.-Y., TOLGA, Y., SULE, C., UMIT, T., AYSE BANU, E., MUHITTIN, T., TIMUR, K., Int. J. Ophthalmol., 7, nr. 3, 2014, p. 534-540 13. ALLEN, K., BERLIN, A.J., Ophtalmic Surg., 20, 1989, p. 486-489 14. SEONG CHAN, C., HYE SUN, C., J AE WOO, J., SUNG J0O, K., JUNG HYE, L., Korean J. Ophthalmol, 31, nr. 1, 2017 FEB, p. 1-8

Manuscript received: 12.10.2017 